\title{
Cephalometric Evaluation of Main Airway Dimensions in Subjects with Different Growth Patterns and their Relation to Patients' Ages and Genders
}

\section{Rabaa Mahmoud Aboubakr ${ }^{1 *}$, Nabeela Hassan Almalki², Sohir Shehata Kamel ${ }^{3}$, Salah Awad Alanazi ${ }^{4}$, Saleh Hassan Alqhtani ${ }^{4}$, Abdullah Ali Almulhim ${ }^{4}$ and Osama Mesfer Alkhathami ${ }^{4}$}

${ }^{1}$ Associate Professor of Dental Public Health and Preventive Dentistry, Mansoura University, Mansoura City, Egypt

${ }^{2}$ Saudi Board of Orthodontic, Ministry of Health, Riyadh, KSA

${ }^{3}$ Alfarabi College of Dentistry and Nursing, Riyadh, KSA

${ }^{4}$ Intern Student at Alfarabi College of Dentistry and Nursing, Riyadh, KSA

*Corresponding Author: Rabaa Mahmoud Aboubakr, Associate Professor of

Dental Public Health and Preventive Dentistry, Mansoura University, Mansoura

City, Egypt.
Received: September 17, 2020

Published: October 28, 2020

(C) All rights are reserved by Rabaa Mahmoud Aboubakr., et al.

\begin{abstract}
Background: Airway shape and dimensions has been attracted attention during the past few decades, this is can be attributed to the relationship between upper airway configuration and sleep-disordered breathing as well as its relation to craniofacial morphology in general.

Objectives: This study was conducted to 1 . Compare the pharyngeal dimensions of subjects with different vertical growth patterns. 2. Assess the impact of modifying variables like age, and gender on airway dimensions.

Materials and Methods: Data collection was based on both cephalometric radiographs and patients' files analysis. Radiographs were grouped according to patients' ages, genders, and vertical growth pattern. Lateral cephalometric radiographs were taken using a standardized technique. SN-MP angle used to divide the sample into hypodivergent, noromodivergent, hyperdivergent growth patterns with values of $<26^{\circ}, 26-38^{\circ}$, and $>38^{\circ}$ respectively as proposed by Isaacson., et al. The upper and lower pharyngeal airways width measured by using McNamara's airway analysis.

Results: the widest upper and lower pharyngeal widths were found among hypodivergent subjects $(20.1 \pm 2.3$ and $11.6 \pm 4)$ respectively, gender differences were found in upper pharyngeal width but in the lower $(17.4 \pm 3.4$ and $18.1 \pm 3.5$, 10.1 \pm 2.3 and $10.2 \pm 3.1)$ for males and females in upper and lower airways respectively. Increasing subject's ages significantly increased upper pharyngeal width but did not affect lower pharyngeal width.

Conclusion: hypodivergent patients had higher upper and lower pharyngeal width when compared to noromodivergent and hyperdivergent growth patterns. Also the UPW and LPW were slightly higher in females than in males. And increasing the age had significantly increased UPW but did not affect LPW.
\end{abstract}

Keywords: Cephalometric Radiographs; Age; Gender; Vertical Growth; Airway Dimensions

\section{Abbreviations}

UAS: Upper Airway Space; OSA: Obstructive Sleep Apnea; MRI: Magnetic Resonance Imaging; UPW: Upper Pharyngeal Width; LPW: Lower Pharyngeal Width; UPA: Upper Pharyngeal Airway

\section{Introduction}

Upper airway space (UAS) structures plays a significant role in the development of the craniofacial complex and are key parameters in orthodontic diagnosis and treatment planning [1]. Airway is 
an essential part of craniofacial growth pattern, and any abnormality in the airway may lead to blockage of it partially or completely that can cause mouth breathing [2].

Pharynx is composed of nasopharynx, oropharynx, and laryngopharynx. Pharynx extension is started from cranial base to the level of sixth cervical vertebra. Nasopharynx lined behind the nasal cavity, Oropharynx opened in the oral cavity, Laryngopharynx started from pharyngoepiglottic fold until the sixth vertebra. Pharynx parts are important in the functions of the respiratory and digestive systems [3].

Width of pharyngeal structures can be determined by soft tissues growth of craniofacial skeletal structures. Subjects with Vertical growth patterns have narrower airway compared to subjects with normal growth patterns that's may lead to an increase of airflow resistance [4].

Sometimes vertical growth patterns of condyles become greater than facial patterns that may affect on mandibular position and bite motion during growth period, consequently, discrepancy occurs between airway pattern and maxillary or mandibular patterns [5]. Orthodontic diagnosis and treatment planning impacts on respiratory system. There is a relationship between nasopharynx, and oropharynx growth with the skull growth. Early proper diagnosis of airway dimensions [mostly vertical one] during orthodontic treatment helps to prevent airway problems in growth periods [6]. Also, some patients with large soft palate may have airway problems like obstructive sleep apnea (OSA) [7].

Several studies demonstrated relationship between airway dimensions and different sagittal and vertical facial growth patterns at different degrees. Skeletal structures abnormalities like; retrusion of the maxilla or mandible, and vertical maxillary overgrowth in high angle patients may restrict anteroposterior dimensions of the airway [8].

Hereditary factors have deleterious effect on human face and Pharyngeal airway, also treatment of breathing disorders may have an impact on airway size. Changing of pharyngeal airway depth occurs during the transformation from mixed dentition period to adult dentition period [9]. Normal upper pharyngeal airway space is 15 - $20 \mathrm{~mm}$, while lower pharyngeal airway (LPA) space is 11 - 14 $\mathrm{mm}[10]$.

There are many tools that are used to measure the airway space, which are of two types: two dimensional and three dimen- sions' tools. Cephalometric radiographs have been used to evaluate facial growth and development [11,12]. Lateral Cephalometric is accessible and suitable for evaluation of craniofacial and soft tissues deformities and enables analysis of dental and skeletal anomalies [13].

Many studies have assessed the anatomic conformation of the upper airway with more sophisticated and expensive techniques, including cine-computed tomography [14], fluoroscopy [15], acoustic reflection [16], fiberoptic pharyngoscopy [17], and magnetic resonance imaging [18]. Computed tomography CT has an important role in measuring upper airway in patients with OSA and patients with acromegaly, however the major disadvantages are high cost and dose [19]. Magnetic Resonance Imaging MRI measures the maximum thickness and length of the soft palate [20]. Polysomnography attend setting (sleep laboratory) has been a reference standard for diagnosis of OSA [21].

Cephalometry is, however, less expensive, more useful, easily achieved with reduced radiation, and correlates with other investigations such as computed tomography (CT) or somnofluoroscopy carried out during wakefulness or sleep $[22,23]$.

Cephalometric measurements of the posterior airway space, although a two-dimensional analysis, have proved very reliable in diagnosing pharyngeal volumes [24,25]. Posterior airway space, as measured by lateral cephalometric radiography, was highly correlated with measurements using three-dimensional CT scan, with a $92 \%$ accuracy in predictability [26].

Muto., et al. proposed that the anteroposterior size of the pharyngeal airway varies on patients with a normal mandible, mandibular retrognathism, and mandibular prognathism. The anteroposterior position of the mandible may impact on the place of the base of the tongue, because the tongue is attached to the inner surface of the anterior mandible by the genioglossus muscle [27].

Understanding of the upper airway in normal subjects can assist in management of obstructive sleep apnea (OSA), and in identifying potential sites of obstruction of the upper airway after surgical correction of dentofacial deformities [28], and Inflammation of the adenoid gland that may obstruct the airway [29].

Several factors like; allergies, environmental irritants, and infections may predispose to airway obstruction [4]. Patients display this pattern typically have narrow lip incompetency, a narrow maxillary arch, and a greater than normal mandibular plane angle 
known as "long face syndrome " that result due to the chronic nasal obstruction cause hyperdivergent [30].

The recognition of age and gender related differences in the dimensions of the upper airway space (UAS) made it necessary to identify reference norms for male and female, also for children and adults. Currently, there is moderate documentation of representative cephalometric characteristics of the UAS in various age and gender groups, which is practically lacking in Middle Eastern populations [31].

\section{Aim of the Study}

The aims of the present retrospective study are to 1 . Compare the pharyngeal dimensions of subjects with different vertical growth patterns. 2. Assess the impact of modifying variables like age, and gender on UAS dimensions.

\section{Materials and Methodology}

\section{Materials}

This retrospective study was conducted in Al-Riyadh city, using 200 cephalometric radiographs for subjects with ages were ranging from 16 - 45 years old of both genders. The radiographs were collected from Eastern Riyadh Specialist Dental Center.

Convenient nonrandomized sampling technique was used for patient allocation. Subjects having any history of congenital defect, orthodontic treatment, surgery in the head and neck region, joint disorder, cervical spine disorder and any neuromuscular disorder or history of nasal obstruction were excluded from the study group.

Ethical approval was taken from The Ethical Committee of Scientific Research at Al-Farabi College of dentistry and nursing in $\mathrm{Al}$ Riyadh city and then from the Saudi ministry of health (Appendix 1 and 2).

\section{Methods}

Data collection was based on both cephalometric radiographs and patients' files analysis. First the radiographs were divided into three groups according to patients' ages; group I for ages 16 - 25, group II for ages 26 - 35, group III for ages 36 - 45, then each age group was sorted into two subgroups according to the patients' gender. Second the collected radiographs were verified for their accuracy and reliability through two well trained and calibrated examiners.

\section{Standardization technique}

Lateral cephalometric radiographs were taken using a standardized technique, with the jaw in centric relation and the teeth in occlusion, the lips relaxed, and the head in the natural head position [32] by the same operator with a cephalostat (Vatech- Pax400C, Korea), as confirmed from the dental center from which the radiographs were collected.

\section{Cephalometric analysis}

Each subgroup was divided into three groups according to vertical growth pattern of the mandible. SN-MP angle used to divide the sample into hypodivergent, normodivergent, hyperdivergent growth patterns with values of $<26^{\circ}, 26-38^{\circ}$ and $>38^{\circ}$ respectively as proposed by Isaacson., et al. [33]. The upper and lower pharyngeal airways width measured by using McNamara's airway analysis [31]. Upper pharyngeal width is taken as a point on the posterior outline of the soft palate to the closest point on the posterior pharyngeal wall. Lower pharyngeal width measured from the point of intersection of the posterior border of the tongue and the inferior border of the mandible to the closest point on the posterior pharyngeal wall.

\section{Statistical analysis}

The statistical analysis was carried out using SPSS (Version 20). Normal distribution of the data was done using KolmogorovSmirnova and Shapiro-Wilk test, these tests indicated that, data displayed was not normally distributed. Hence nonparametric test were applied. Descriptive statistics used for data summarization and presentation. Mann- Whitney $U$ test and Kruskal-Wallis test applied to compare the difference between 2 and more than 2 variables respectively. A 2 -sided $\mathrm{p}<0.05$ will be considered as statistically significant.

\section{Results}

The Kruskal-Wallis test is used to compare the Pharyngeal width among cephalometric angulation groups. UPW expressed statistical significant difference between the different cephalometric angulations $(\mathrm{P}=0.001)$ whereas LPW did not show a significant difference $(P=0.152)$ (Table 1 and graph 1$)$.

The Mann- Whitney $U$ test is used to compare the Pharyngeal width among separate cephalometric angulation groups. Statistics showed a statistically significant $(P=0.001)$ higher width among 
Cephalometric Evaluation of Main Airway Dimensions in Subjects with Different Growth Patterns and their Relation to Patients' Ages and Genders

hypo-divergent angulation group compared to hyper divergent group among UPW. Similarly, normo-divergent angulation group displayed statistically significant higher width compared to Hyperdivergent angulation group among UPW (Table 2).

\begin{tabular}{|c|c|c|c|c|c|}
\hline Group & Angulation & $\mathbf{N}$ & $\begin{array}{l}\text { Mean } \pm \\
\text { SD }\end{array}$ & $\begin{array}{l}\text { Mean } \\
\text { Rank }\end{array}$ & $\begin{array}{c}\mathbf{P} \\
\text { Value }\end{array}$ \\
\hline \multirow[t]{3}{*}{ UPW } & Hypo-divergent & 14 & $20.1 \pm 2.3$ & 142.14 & \multirow[t]{3}{*}{$0.001^{*}$} \\
\hline & $\begin{array}{l}\text { Normo-diver- } \\
\text { gent }\end{array}$ & 107 & $19.2 \pm 3.01$ & 122.98 & \\
\hline & $\begin{array}{l}\text { Hyper-diver- } \\
\text { gent }\end{array}$ & 79 & $15.7 \pm 3.1$ & 62.68 & \\
\hline \multirow[t]{3}{*}{ LPW } & Hypo-divergent & 14 & $11.6 \pm 4$ & 123.64 & \multirow[t]{3}{*}{0.152} \\
\hline & $\begin{array}{l}\text { Normo-diver- } \\
\text { gent }\end{array}$ & 107 & $10.4 \pm 2.7$ & 102.93 & \\
\hline & $\begin{array}{l}\text { Hyper-diver- } \\
\text { gent }\end{array}$ & 79 & $9.8 \pm 2.8$ & 93.1 & \\
\hline
\end{tabular}

Table 1: Comparison of different cephalometric angulation among upper and lower pharyngeal width.

*Statistical significance set at 0.05 .

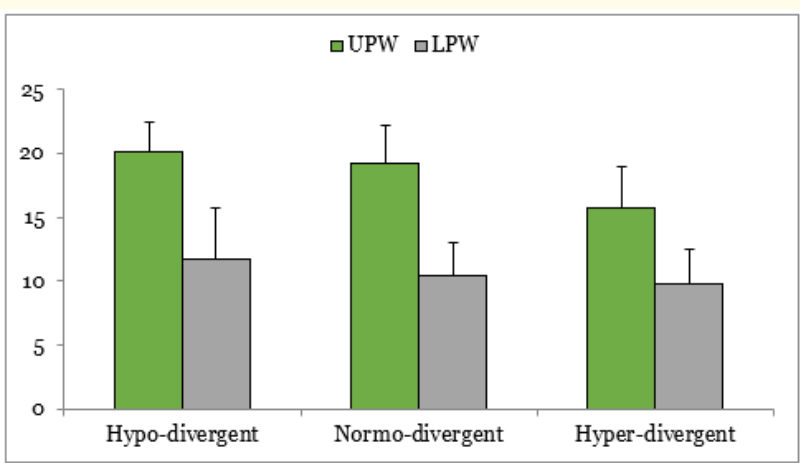

Graph 1: Mean distribution of upper and lower pharyngeal width among different cephalometric angulation.

\begin{tabular}{|l|c|c|c|c|}
\hline \multirow{2}{*}{ Group } & Angulation & $\mathbf{N}$ & $\begin{array}{c}\text { Mean } \\
\text { Rank }\end{array}$ & $\begin{array}{c}\text { P } \\
\text { Value }\end{array}$ \\
\hline \multirow{4}{*}{ UPW } & Hypo-divergent & 14 & 72.57 & 0.186 \\
\cline { 2 - 4 } & Normo-divergent & 107 & 59.49 & \\
\cline { 2 - 4 } & Hypo-divergent & 14 & 77.07 & \multirow{2}{*}{$0.001^{*}$} \\
\cline { 2 - 4 } & Hyper-divergent & 79 & 41.67 & \\
\cline { 2 - 4 } & Normo-divergent & 107 & 117.49 & $0.001^{*}$ \\
\cline { 2 - 4 } & Hyper-divergent & 79 & 61.01 & \\
\hline
\end{tabular}

Table 2: Multiple comparison of different cephalometric angulation among upper and lower pharyngeal width.

*Statistical significance set at 0.05 .
The Mann- Whitney U test is used to compare the Pharyngeal width among males and females. There is no significant difference between males and females in relation to both UPW and LPW (Table 3 and graph 2).

\begin{tabular}{|l|c|c|c|c|c|}
\hline Groups & Sex & $\mathbf{N}$ & Mean \pm SD & $\begin{array}{c}\text { Mean } \\
\text { Rank }\end{array}$ & $\begin{array}{c}\text { P } \\
\text { Value }\end{array}$ \\
\hline \multirow{2}{*}{ UPW } & Male & 75 & $17.4 \pm 3.4$ & 93.09 & 0.159 \\
\cline { 2 - 5 } & Female & 125 & $18.1 \pm 3.5$ & 104.95 & \\
\hline \multirow{2}{*}{ LPW } & Male & 75 & $10.1 \pm 2.3$ & 101.98 & \multirow{2}{*}{0.778} \\
\cline { 2 - 5 } & Female & 125 & $10.2 \pm 3.1$ & 99.61 & \\
\hline
\end{tabular}

Table 3: Comparison of upper and lower pharyngeal width among males and females.

*Statistical significance set at 0.05 .

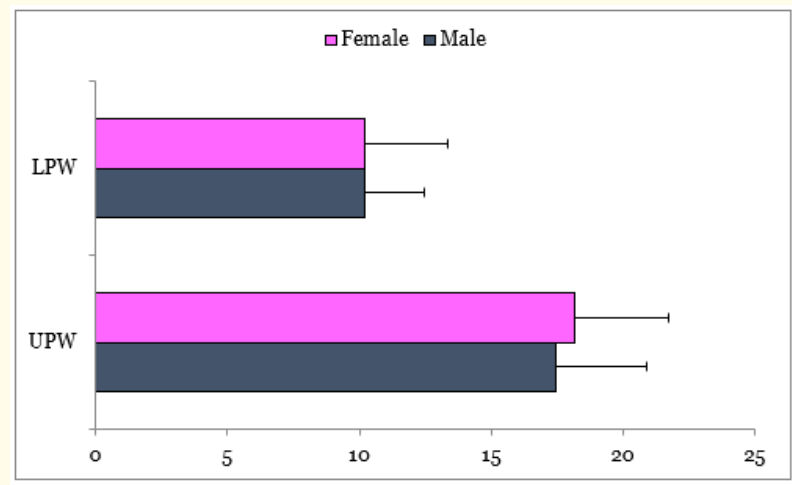

Graph 2: Mean distribution of upper and lower pharyngeal width among different genders.

The Kruskal-Wallis test is used to compare the Pharyngeal width among different age-groups. UPW expressed statistical significant difference between the different age-groups $(\mathrm{P}=0.005)$ whereas LPW did not show a significant difference $(P=0.777)$ (Table 4 and graph 3).

\begin{tabular}{|c|c|c|c|c|c|}
\hline & Age & N & $\begin{array}{c}\text { Mean } \pm \\
\text { SD }\end{array}$ & $\begin{array}{c}\text { Mean } \\
\text { Rank }\end{array}$ & $\begin{array}{c}\text { P } \\
\text { Value }\end{array}$ \\
\hline \multirow{3}{*}{ UPW } & GI (16-25) & 118 & $17.2 \pm 3.6$ & 89.42 & $0.005^{*}$ \\
\cline { 2 - 5 } & GII (26-35) & 58 & $18.9 \pm 3.2$ & 116.57 & \\
\cline { 2 - 5 } & GIII (36-45) & 24 & $18.9 \pm 2.6$ & 116.17 & \\
\hline \multirow{2}{*}{ LPW } & GI (16-25) & 118 & $10.2 \pm 2.9$ & 102.53 & \multirow{2}{*}{0.777} \\
\cline { 2 - 5 } & GII (26-35) & 58 & $10.1 \pm 2.6$ & 99.16 & \\
\cline { 2 - 5 } & GIII (36-45) & 24 & $10.1 \pm 3.3$ & 93.79 & \\
\hline
\end{tabular}

Table 4: Comparison of upper and lower pharyngeal width among different age-groups.

*Statistical significance set at 0.05. GI: Group I; GII: Group II; GIII: Group III. 


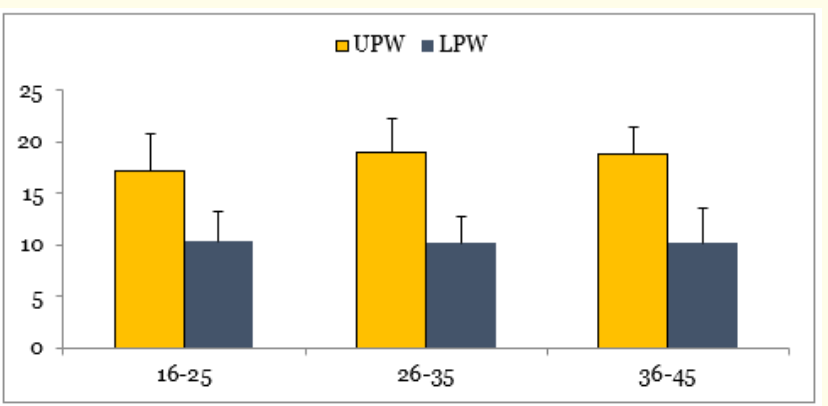

Graph 3: Mean distribution of upper and lower pharyngeal width among different age-groups.

The Mann- Whitney U test is used to compare the Pharyngeal width among individual age-groups. Statistics showed a statistically significant $(\mathrm{P}=0.004)$ higher width among 26 - 35 age-group compared to 16 - 25 age-group among UPW. Similarly, 36 - 45 agegroup displayed statistically significant higher width compared to 16 - 25 age-group among UPW (Table 5).

\begin{tabular}{|c|c|c|c|c|}
\hline & Age & N & Mean Rank & P Value \\
\hline \multirow{4}{*}{ UPW } & GI (16-25) & 118 & 80.77 & \multirow{2}{*}{$0.004^{*}$} \\
\cline { 2 - 4 } & GII (26-35) & 58 & 104.22 & \\
\cline { 2 - 4 } & GI (16-25) & 118 & 68.14 & \multirow{2}{*}{$0.03^{*}$} \\
\cline { 2 - 4 } & GIII (36-45) & 24 & 88 & \\
\cline { 2 - 4 } & GII (26-35) & 58 & 41.84 & \multirow{2}{*}{0.838} \\
\cline { 2 - 4 } & GIII (36-45) & 24 & 40.67 & \\
\hline
\end{tabular}

Table 5: Intergroup comparison of upper and lower pharyngeal width among different age-groups.

*Statistical significance set at 0.05. GI: Group I; GII: Group II; GIII: Group III.

\section{Discussion}

In the present study the assessment tool of pharyngeal airway dimensions was Cephalometric radiographs. Controversy exists as the Cephalogram measure two-dimensional views of three-dimensional structures. However, we chose lateral cephalograms as was highly correlated with another measurement techniques like the three-dimensional CT scan, with 92\% accuracy as evidenced in Riley., et al. (1990) study [26]. Also, Aboudara., et al. (2009) [34] compared CT and cephalometric radiographs and found a significant positive relationship between nasopharyngeal airway size on lateral Cephalogram and its true volumetric size as determined from CT scan. Cephalometry has several advantages in comparison to other radiographic techniques like: low cost and minimal exposure to radiation.

Our results revealed that, the mean upper airway width (UAW) was higher for hypodivergent subjects followed by noromodivergent subjects, then hyperdivergent subjects which was the least. In the comparison between angulations groups in upper airway width found that the hyperdivergent group showed statistically significant differences comparing to hypodivergent, and noromodivergent groups. Regarding the mean lower airway width, it showed the same sequence as in UAW without statistical significant difference between different angulations.

These finding was matched with those of Ucar., et al. (2011) [35] who reported larger upper pharyngeal airway space in low angle subjects than in high angle subjects. Also Joseph., et al. (1998) [30] mentioned that hyperdivergent subjects showed a narrower anteroposterior pharyngeal dimension than noromodivergent subjects. Furthermore, Memon., et al. (2012) [8] showed that hyperdivergent facial pattern subjects had narrow upper pharyngeal airway width as compared to noromodivergent and hypodivergent.

On the other hand, Ansar., et al. (2015), reported that hyperdivergent growth pattern subjects showed a statistically significantly narrow upper and lower pharyngeal airway width when compared to noromodivergent and hypodivergent facial patterns. They explained their results that, the small pharyngeal width in hyperdivergent subjects could be attributed to downward and backward rotation of mandible that might lead to a posterior tongue position and increasing the chances of impaired respiratory function. They also cleared that, the "reduction" of the pharyngeal airway in hyperdivergent patients cannot be attributed only to the larger adenoids or the presence of soft tissue in the posterior nasopharyngeal region and there may be another factors that not fully understood [2].

Concerning gender, females showed higher mean upper pharyngeal airway width (UPW) in comparison to males. However, for mean LPW, it was nearly equal for both genders. There were no any significant differences between both genders regarding UPW and LPW. Our finding can be explained by Sexual dimorphism which is a usual finding in investigations evaluating pharyngeal morphometry in healthy young adults [36]. 
Our results matched with Daraze., et al. (2017) [37], who reported larger UPW in females than in males. However, our finding was not consistent with the findings of young adult European Spanish [36] and Chinese [38] populations, where there was no gender related differences in the minimum depth of the airway. Also, Mislik., et al. [39] and Abramson., et al. [40] demonstrated no gender related difference regarding airway dimensions.

For age effect, it was found that UPW increased by increasing age, but LPW did not affected by age. Our finding disagreed with Mislik., et al. [39] who cleared no radical change in the upper airway dimensions between 6 and 17 years of age and explained this by the formation and maturation of upper airway dimensions in early periods.

\section{Conclusion}

Our results cleared that, hypodivergent patients had higher upper and lower pharyngeal width when compared to noromodivergent and hyperdivergent growth patterns. Also, the UPW and LPW were slightly higher in females than in males. And increasing the age had significantly increased UPW but did not affect LPW.

\section{Recommendations}

- To obtain more valid data similar studies should be conducted on larger sample size.

- Three-dimensional assessment techniques may be more accurate in recording three-dimensional structure than two dimensions' technique.

\section{Bibliography}

1. Lowe AA., et al. "Cephalometric comparisons of craniofacial and upper airway structure by skeletal subtype and gender in patients with obstructive sleep apnea". American Journal of Orthodontics and Dentofacial Orthopedics 110.6 (1996): 653664.

2. Ansar J., et al. "Cephalometric evaluation of the airway dimensions in subjects with different growth patterns". Journal of Orthodontic Research 3 (2015): 108-112.

3. Eylan İ and Oktay H. "A study on the pharyngeal size in different skeletal patterns". American Journal of Orthodontics and Dentofacial Orthopedics 108.1 (1995): 69-75.

4. Flores B AP., et al. "Comparison of airway dimensions in skeletal Class I malocclusion subjects with different vertical facial patterns". Dental Press Journal of Orthodontic 22.6 (2017): 35-42.

5. Iqbal N., et al. "Comparison of different craniofacial patterns with pharyngeal widths". JKCD 6 (2015): 20-24.
6. Lakshmi K B., et al. "Comparison between Growth Patterns and Pharyngeal Widths in Different Skeletal Malocclusions in South Indian Population". Journal of International Society of Preventive and Community Dentistry 8 (2018): 224-228.

7. Gungor AY and Turkkahraman H. "Effects of airway problems on maxillary growth: a review". European Journal of Dentistry 3.3 (2009): 250-254.

8. Memon S., et al. "Comparison of different craniofacial patterns with pharyngeal widths". Journal of the College of Physicians and Surgeons Pakistan 22 (2012): 302-306.

9. Chang M S., et al. "Developmental Changes in Pharyngeal Airway Depth and Hyoid Bone Position from Childhood to Young Adulthood". Angle of Orthodontics 79.3 (2009): 484-490.

10. Mani P., et al. "Upper and lower pharyngeal airway space in West-Tamil Nadu population". Journal of Pharmacy and Bioallied Sciences 7.6 (2015): 539-542.

11. Steiner C C. "Cephalometric in clinical practice". Angle of Orthodontics 29.1 (1959): 8-29.

12. Khouw FE., et al. "Cephalometric evaluation of patients with dentofacial disharmonies requiring surgical correction". Oral Surgery 29 (1970): 789-798.

13. Mukaihara K., et al. "Evaluation of the pharyngeal airway using computational fluid dynamics in patients with acromegaly". Laryngoscope Investigation Otolaryngology 3 (2018): 133-138.

14. Haponik E F., et al. "Computerized tomography in obstructive sleep apnea. Correlation of airway size with physiology during sleep and wakefulness". American Review of Respiratory Disease 127 (1983): 221-226.

15. Suratt PM., et al. "Fluoroscopic and computed tomographic features of the pharyngeal airway in obstructive sleep apnea". American Review of Respiratory Disease 127 (1983): 487-492.

16. Bradley T D., et al. "Pharyngeal size in snorers, nonsnorers, and in patients with obstructive sleep apnea". The New England Journal of Medicine 315 (1986): 1327-1331.

17. Remmers J E., et al. "Pathogenesis of upper airway occlusion during sleep". Journal of Applied Physiology 44 (1978): 931938.

18. Rodenstein D 0., et al. "Pharyngeal shape and dimensions in healthy subjects, snorers, and patients with obstructive sleep apnoea". Thorax 45 (1990): 722-727.

19. RyuH H., et al. "The usefulness of cephalometric measurement as a diagnostic tool for obstructive sleep apnea syndrome: a retrospective study". Oral Surgery, Oral Medicine, Oral Pathology, and Oral Radiology 119 (2015): 20-31. 
20. Barrera J E., et al. "Anatomic measures of upper airway structures in obstructive sleep apnea". World Journal of Otorhinolaryngology - Head and Neck Surgery 3.2 (2017): 85-91.

21. "Polysomnography in patients with obstructive sleep apnea: an evidence-based analysis". Ontario Health Technology Assessment Series 6 (2006): 1-38.

22. Maltais F., et al. "Cephalometric measurements in snorers, non-snorers, and patients with sleep apnoea". Thorax 46 (1991): 419-423.

23. Pepin JL., et al. "Somnofluoroscopy, computed tomography, and cephalometry in the assessment of the airway in obstructive sleep apnoea". Thorax 47 (1992): 150-156.

24. deBerry BB., et al. "Cephalometric analysis for diagnosis and treatment of obstructive sleep apnea". Laryngoscope 98 (1988): 226-234.

25. Riley R., et al. "Cephalometric analysis and flow-volume loops in obstructive sleep apnea patients”. Sleep 6 (1983): 303-311.

26. Riley R W and Powell N B. "Maxillofacial surgery and obstructive sleep apnea syndrome". Otolaryngologic Clinics of North America 23 (1990): 809-826.

27. MUTO T., et al. "A cephalometric evaluation of the pharyngeal airway space in patients with mandibular retrognathia and prognathia, and normal subjects". International Journal of Oral and Maxillofacial Surgery 37 (2008): 228-231.

28. Samman N., et al. "Cephalometric norms for the upper airway in a healthy Hong Kong Chinese population". Citation Hong Kong Medical Journal 9.7 (2003): 25-30.

29. SIMSEK G., et al. "Blood parameters as indicators of upper airway obstruction in children with adenoid or adenotonsillar hypertrophy". Journal of Craniofacial Surgery 26 (2015) e213216.

30. JOSEPH AA., et al. "A cephalometric comparative study of the soft tissue airway dimensions in persons with hyperdivergent and normodivergent facial patterns". Journal of Oral and Maxillofacial Surgery 56 (1998): 135-139; discussion 139-140.

31. J A McNamara Jr. "A method of cephalometric evaluation". American Journal of Orthodontics 86.6 (1984): 449-469.

32. Solow B and Tallgre A. "Natural head position in standing subjects". Acta Odontologica Scandinavica 29 (1971): 591-607.

33. Isaacson J R., et al. "Extreme variation in vertical facial growth and associated variation in skeletal and dental relations". Angle of Orthodontics 41 (1971): 219-229.
34. Aboudara C., et al. "Comparison of airway space with conventional lateral headfilms and 3-dimensional reconstruction from cone-beam computed tomography". American Journal of Orthodontics and Dentofacial Orthopedics 135 (2009): 468479.

35. Ucar F I and Uysal T. "Orofacial airway dimensions in subjects with Class I malocclusion and different growth patterns". Angle of Orthodontics 81 (2011): 460-468.

36. Martin., et al. "Comparative study of nasopharyngeal softtissue characteristics in patients with Class III malocclusion". American Journal of Orthodontics and Dentofacial Orthopedics 139.2 (2011): 242-225.

37. Daraze A., et al. "Cephalometrics of Pharyngeal Airway Space in Lebanese Adults". International Journal of Dentistry (2017): 11.

38. Samman N., et al. "Cephalometric norms for the upper airway in a healthy Hong Kong Chinese population". Hong Kong Medical Journal 9.1 (2003) 25-30.

39. Mislik B., et al. "Pharyngeal airway dimensions: a cephalometric, growth-study based analysis of physiological variations in children aged 6-17". European Journal of Orthodontics 36 (2014): 331-339.

40. Abramson Z., et al. "Age-related changes of the upper airway assessed by 3-dimensional computed tomography". Journal of Craniofacial Surgery 20 (2009): 657-663.

\section{Assets from publication with us}

- Prompt Acknowledgement after receiving the article

- Thorough Double blinded peer review

- Rapid Publication

- Issue of Publication Certificate

- High visibility of your Published work

Website: www.actascientific.com/

Submit Article: www.actascientific.com/submission.php

Email us: editor@actascientific.com

Contact us: +919182824667 